\title{
The Effects of Group Cognitive Behavioral Therapy on the Improvement of Depression and Anxiety in Adolescents with Problematic Internet Use
}

\author{
Sang-Hyun Kim¹, Hyeon-Woo Yim², Sun-Jin $\mathrm{Jo}^{2}$, Kyu-In Jung ${ }^{3}$, Kina Lee ${ }^{4}$, and Min-Hyeon Park \\ ${ }^{1}$ Department of Psychiatry, Uijeongbu St. Mary's Hospital, The Catholic University of Korea College of Medicine, Uijeongbu, Korea \\ ${ }^{2}$ Department of Preventive Medicine, The Catholic University of Korea College of Medicine, Seoul, Korea \\ ${ }^{3}$ Department of Psychiatry, St. Paul's Hospital, The Catholic University of Korea College of Medicine, Seoul, Korea \\ ${ }^{4}$ Seoul St. Mary's Hospital, The Catholic University of Korea, Seoul, Korea
}

\begin{abstract}
Objectives: The overuse of the Internet among adolescents has increased dramatically in recent years, leading to pathological or problematic Internet use. Cognitive behavioral therapy (CBT) is known to be effective for the treatment of problematic Internet use, particularly for adolescents. The aim of the present study was to evaluate the therapeutic efficacy of group CBT for problematic Internet use in adolescents.

Methods: A total of 17 patients aged 12-17 years who met Young's diagnostic questionnaire criteria of problematic Internet use participated in a school-based eight-session group CBT program. The level of problematic Internet use among participating students was measured using Young's Internet Addiction Scale (IAS). Depression and anxiety levels were evaluated using the Children's Depression Inventory (CDI) and the State-Trait Anxiety Inventory (STAI), respectively. Each construct was assessed at baseline, immediately after the intervention, and at a one-month follow-up visit. Statistical significance was based on a p-value of $<0.05$.

Results: Immediately after the program, the IAS, CDI, and State Anxiety Inventory (SAI) scores were significantly lower than before the program. At the one-month follow-up assessment, the IAS scores remained low, and the CDI and SAI scores were even lower than immediately after the program.

Conclusion: Group CBT was effective for adolescents with problematic Internet use, and was also demonstrated to improve depression and anxiety.
\end{abstract}

Key Words: Problematic Internet use; Depression; Anxiety; Group cognitive behavioral therapy.

Received: October 16, 2017 / Revision: December 19, 2017 / Accepted: January 12, 2018

Address for correspondence: Min-Hyeon Park, Department of Psychiatry, The Catholic University of Korea, St. Paul's Hospital, 180 Wangsan-ro, Dongdaemun-gu, Seoul 02559, Korea

Tel: +82-2-958-2153, Fax: +82-31-847-3630, E-mail: neominnie@daum.net

\section{INTRODUCTION}

As of 2015, 96.6\% of Korean teenagers are using the Internet at least once a day, and the average usage time is 14.5 hours a week. ${ }^{1 .}$ However, as problems related to the use of the Internet have become increasingly evident, the term 'Internet addiction' has received much attention. The term 'Internet addiction' was coined by Goldberg ${ }^{2)}$ and was defined as the pathological and compulsive use of the Internet. Young proposed diagnostic criteria for problematic Internet use according to the Diagnostic and Statistical Manual of Mental Disorders-fourth edition (DSM-IV) ${ }^{3)}$ pathological gambling diagnostic criteria. ${ }^{4)}$ However, the definition of prob-

This is an Open Access article distributed under the terms of the Creative Commons Attribution Non-Commercial License (http://creativecommons.org/licenses/by-nc/4.0) which permits unrestricted non-commercial use, distribution, and reproduction in any medium, provided the original work is properly cited. lematic Internet use remains controversial, and the DSM-5, which is currently being revised, does not have problematic Internet use diagnostic criteria because it is difficult to define as a disease. Only Internet gaming disorder has been categorized as a diagnosis requiring further study.

In a number of studies, problematic Internet use has been associated with depression, anxiety disorders, social phobia, substance-related disorders, obsessive-compulsive disorder, attention deficit hyperactivity disorder, and impulse control disorder. ${ }^{5-7)}$ Problematic Internet use is particularly serious in children and adolescents. According to the Internet addiction survey in 2014, $12.5 \%$ of adolescents were found to be at risk of Internet addiction, ${ }^{8)}$ and the problematic Internet use of children and adolescents is known to negatively affect academic achievement and family relationships. ${ }^{9,10)}$

As demonstrated by definitions of Internet addiction, ${ }^{4)}$ 
problematic Internet use is also understood to be a behavioral addiction with 'tolerance' and 'withdrawal' symptoms, and has neuropsychological and pathological mechanisms similar to those of other substance use disorders or gambling disorders. ${ }^{11-13)}$ Alcohol use disorder and gambling disorder treatment programs are primarily based on cognitive behavioral models. ${ }^{14)}$ Through cognitive behavioral therapy (CBT), patients become more aware of addictive behaviors and emotions, and the thoughts that cause them, and realize that they are repeating their addictive behaviors in certain dynamics. Therefore, CBT can be introduced to treat problematic Internet use. In particular, group interventions are advantageous in terms of efficiency, provision of alternative learning opportunities, and peer feedback when there are many subjects with relatively homogeneous characteristics, ${ }^{15,16)}$ and are practiced universally for the treatment of problematic Internet use. ${ }^{17)}$ In addition, the subjects will deal with their emotional state by examining the causes of the Internet use in the treatment process. Therefore, it is thought that emotions will also be affected.

Therefore, this study applied group CBT for treatment of problematic Internet use among Korean adolescents who have easy access to the Internet, and attempted to identify associated depression and anxiety symptoms along with strategies for mitigation and maintenance of effects.

\section{METHODS}

\section{Subjects}

This study was conducted as part of a project for the Promotion of Child and Adolescent Mental Health in the mental health center of Seocho-gu district. The Korean Internet addiction self-report test ${ }^{18)}$ was administered to 389 students (40 female students) in the first and second grade of one industrial high school and 253 students in the first grade of one female middle school, and a high-risk group and a potential risk group were selected. A psychiatrist conducted 1:1 interviews using Young's Diagnostic Questionnaire to exclude false positives from the 48 selected industrial high school students (12.34\%) and 13 female middle school students (5.14\%). Exclusion criteria included the following: 1) no problematic Internet use, as determined in an interview with a psychiatrist, 2) treatment for a psychiatric disorder, 3) currently receiving treatment for problematic Internet use, 4) unwillingness to participate or unwillingness of the students' parents to enroll them in the program, and 5) opposed to participation due to problems such as school classes. A total of 17 students ( 7 industrial high school students and $10 \mathrm{fe}-$ male middle school students) participated in the program.

\section{Procedures, contents, and operation of group programs}

Consent was provided by each student and their parents prior to the program, and the study was approved by the Institutional Review Board of the Catholic University (CUMC09U133). The group CBT program consisted of eight sessions, with two sessions per week, and details of each session are included in Appendix.

\section{Screening scale and effect evaluation scale}

\section{Screening scale}

\section{Korean Internet addiction self-report test (K-scale)}

This is a self-diagnostic scale for measuring tendencies for addiction to Internet use in adolescents, and was developed for Korean adolescents by the National Information Society Agency under the Ministry of Information and Communication.

\section{Young's Diagnostic Questionnaire (YDQ)}

This is a diagnostic questionnaire composed of eight items modified from the DSM-IV's pathological gambling model. If five or more answers are "yes", respondents are classified as problematic Internet users, and if fewer than five answers are "yes", respondents are classified as normal Internet users. ${ }^{4)}$

\section{Effect evaluation scale}

Young's Internet Addiction Scale (IAS)

The Young's Internet Addiction Scale (IAS) is a self-report 20 -item scale with responses of 1 to 5 points for each item. An IAS score of 40-69 points indicates that problems with Internet use are occasional or frequent. A score of $\geq 70$ points is considered to indicate serious problems with Internet use. ${ }^{19)}$

\section{Children's Depression Inventory (CDI)}

This is a self-report scale that evaluates the cognitive, emotional, and behavioral symptoms of childhood depression. ${ }^{20)}$ A score of 22-25 points indicates mild depression, 26-28 points indicates moderate depression, and $\geq 29$ points indicates severe depression.

\section{State-Trait Anxiety Inventory (STAI)}

This measure is composed of 20 items of the State Anxiety Inventory (SAI), which evaluates current anxiety, and 20 items of Trait Anxiety Inventory (TAI), which evaluates anxiety tendency. ${ }^{21)}$ The SAI indicates that a score of 4144 points indicates slightly high current anxiety levels, 4548 points indicates moderately high current anxiety levels, and $\geq 49$ points indicates extremely high current anxiety 
levels. In the TAI, the anxiety tendency is indicated to be slightly high at a score of $39-42$ points, moderately high at 43-46 points, and extremely high at $\geq 47$ points.

\section{Statistical analysis}

The differences in the baseline and post-intervention evaluation scores of the intervention program were analyzed by paired t-tests, and the differences in the pre- and post-followup evaluation indices were analyzed by repeated measures analysis of variances. The differences in the Internet use of the industrial high school students and the female middle school students were analyzed using Fisher's exact test. Statistical significance was based on a $p$-value of $<0.05$. All statistical analyses were performed using SPSS 20.0 for Windows (IBM Corp., Armonk, NY, USA).

\section{RESULTS}

\section{Clinical characteristics and characteristics related to Internet use (Table 1)}

There was no difference in time between the first use of the
Internet and the start of problematic Internet use $(\mathrm{p}=0.287)$. The mean Children's Depression Inventory (CDI) total scores for the two schools were indicative of mild depression. The SAI total scores were higher among industrial high school students, while the scores of female middle school students were within the normal range. The mean TAI total scores of the subjects in the two schools indicated that the level of anxiety tendency was very high.

\section{The effect of program intervention (Table 2)}

A total of 17 students participated until the end of the session, without any dropouts during the 8th session.

The IAS total score decreased significantly in the post-intervention evaluation compared to the baseline evaluation total score $(\mathrm{p}<0.001)$. CDI and SAI total scores also significantly decreased in the post-intervention evaluation ( $\mathrm{p}=0.006$ and $\mathrm{p}<0.0001$, respectively). There was no significant change in the TAI total score $(\mathrm{p}=0.122)$. Thirteen out of 17 students reported a reduction in the amount of time spent using the Internet after the program. Among the students who reported a reduction in Internet usage, the mean Internet us-

Table 1. Internet use pattern of subjects and initial score of rating scales

\begin{tabular}{|c|c|c|}
\hline & Boys $(n=7)$ & Girls $(n=10)$ \\
\hline \multicolumn{3}{|l|}{ Time being spent for Internet use (hours/day) } \\
\hline$<2$ & $1(14.29)$ & $5(50.00)$ \\
\hline $2 \leq-<4$ & $3(42.86)$ & $2(20.00)$ \\
\hline $4 \leq-<8$ & $3(42.86)$ & $2(20.00)$ \\
\hline$\geq 8$ & - & $1(10.00)$ \\
\hline \multicolumn{3}{|l|}{ Peak time of Internet usage } \\
\hline After school-Evening & $1(14.29)$ & $6(60.00)$ \\
\hline Evening-Midnight & $2(28.57)$ & $2(20.00)$ \\
\hline Midnight-Daybreak & $1(14.29)$ & - \\
\hline All day long (If have a chance) & $3(42.86)$ & $2(20.00)$ \\
\hline First time of playing computer game (age) & $8.5(2.07)$ & $8.3(2.31)$ \\
\hline \multicolumn{3}{|l|}{ The date being addicted to Internet } \\
\hline Immediately after Internet use & $4(66.67)$ & $2(22.22)$ \\
\hline 6 month after Internet use & - & $1(14.29)$ \\
\hline 2 year after Internet use & $2(33.33)$ & $6(66.67)$ \\
\hline \multicolumn{3}{|l|}{ Main usage } \\
\hline MMORPG & $4(57.14)$ & $3(30.00)$ \\
\hline RTS & $2(28.57)$ & \\
\hline FPS & & $1(10.00)$ \\
\hline Other contents besides Internet games (chatting or websurfing) & $1(14.29)$ & $6(60.00)$ \\
\hline IAS & $60.2(13.4)$ & $60.3(13.2)$ \\
\hline CDI & $25.6(2.1)$ & $25.7(3.2)$ \\
\hline SAI & $43.4(6.2)$ & $35.2(7.2)$ \\
\hline TAl & $49.9(3.0)$ & 47.7 (3.5) \\
\hline
\end{tabular}

Data present number (percent) or mean (standard deviation). CDI: Children's Depression Inventory, FPS: first person shooting, IAS: Young's Internet Addiction Scale, MMORPG: massive multiplayer online role playing game, RTS: real-time strategy, SAI: State Anxiety Inventory, TAI: Trait Anxiety Inventory 
Table 2. Comparision of pre-and post intervention effect

\begin{tabular}{|c|c|c|c|}
\hline \multirow{2}{*}{ Variables } & Pre & Post & \multirow{2}{*}{ p-value } \\
\hline & \multicolumn{2}{|c|}{ Mean \pm SD } & \\
\hline IAS & $59.88 \pm 12.48$ & $50.71 \pm 10.75$ & $<0.0001$ \\
\hline CDI & $25.65 \pm 2.71$ & $19.00 \pm 7.87$ & 0.006 \\
\hline TAI & $39.06 \pm 7.62$ & $36.65 \pm 8.18$ & $<0.0001$ \\
\hline SAI & $47.71 \pm 5.00$ & $36.06 \pm 6.20$ & 0.122 \\
\hline
\end{tabular}

CDI: Children's Depression Inventory, IAS: Young's Internet Addiction Scale, SAI: State Anxiety Inventory, TAI: Trait Anxiety Inventory

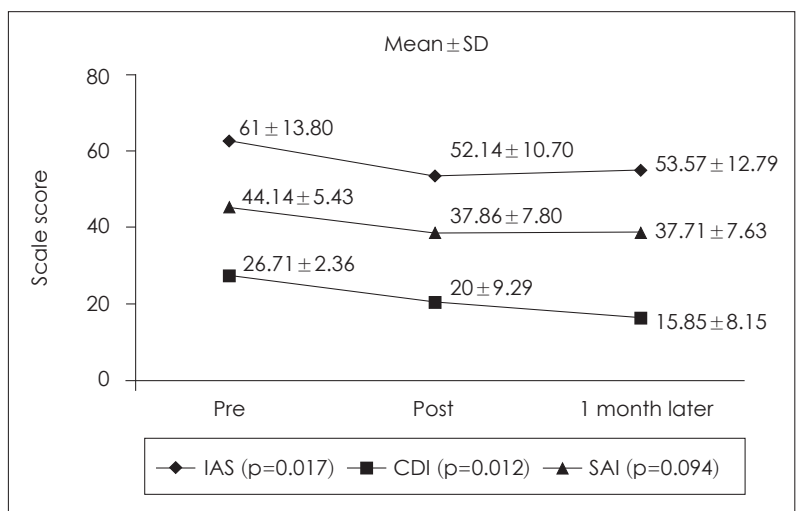

Fig. 1. Score comparison between pre, post intervention and one month later. CDI: Children's Depression Inventory, IAS: Young's Internet Addiction Scale, SAI: State Anxiety Inventory.

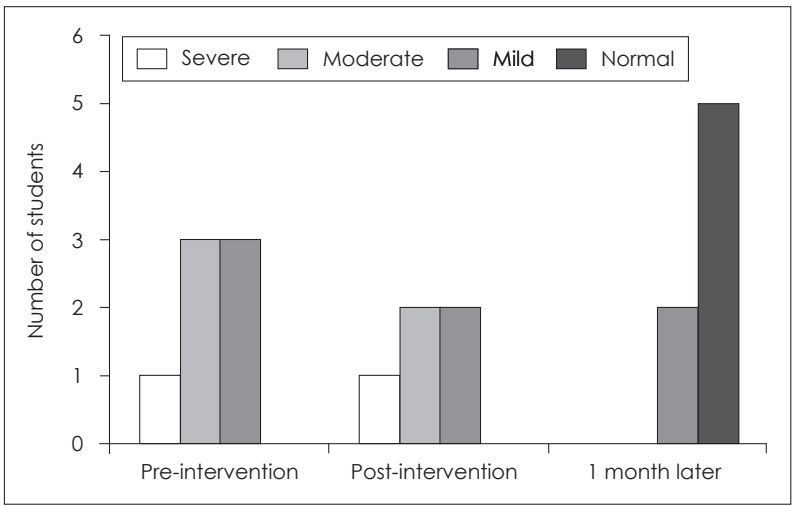

Fig. 2. Number of students according to Children's Depression Inventory score.

age time before the program was 4.75 hours $( \pm 1.94)$, while the average Internet usage time after the program was 2.77 hours $( \pm 1.92)(\mathrm{p}<0.0001)$. After the program, eight students reported an increase in the amount of time spent studying, and nine students reported no change. There were two students who felt that their Internet habits were not harmful after the program, and there were ten students who knew that their Internet usage habits were harmful, but found them hard to correct. A total of five students were advised to correct the harmful Internet habits after the program.



Fig. 3. Number of students according to State Anxiety Inventory score.

\section{Follow-up evaluation}

A total of seven students among the ten female middle school students who participated in the program performed follow-up evaluations 1 month after the end of the program. There were no significant differences in the IAS (pre $\mathrm{p}=0.814$, post $\mathrm{p}=0.723$ ), CDI (pre $\mathrm{p}=0.127$, post $\mathrm{p}=0.601$ ), $\mathrm{SAI}$ (pre $\mathrm{p}=$ 0.076 , post $\mathrm{p}=0.482$ ), and TAI scores (pre $\mathrm{p}=0.422$, post $\mathrm{p}=$ $0.731)$ before and after the follow-up evaluation. Fig. 1 presents the comparison of the baseline and post-intervention scores.

Compared to the IAS, CDI, and SAI pre-intervention scores, the corresponding follow-up scores were low $(\mathrm{p}=0.054,0.015$, 0.058 , respectively). The IAS and SAI scores did not significantly differ between the post-intervention and the followup evaluations ( $\mathrm{p}=0.664,0.961$, respectively). The CDI scores were not significantly different, but the follow-up scores were lower than the post-intervention scores $(\mathrm{p}=0.093)$.

The CDI and SAI scores decreased overall in the follow-up evaluation. The changes in the number of students assigned to each severity category over the three evaluations are presented in Figs. 2 and 3.

\section{DISCUSSION}

In the present study, the IAS scores after the program were significantly lower than the scores before the program, and this effect was maintained in the follow-up evaluation 1 month later. The program allowed the participants to think about alternative activities to using the Internet, and to improve their self-regulation abilities. This finding is consistent with previous studies, indicating a significant decrease in the Internet addiction scores via problematic Internet use group therapy. ${ }^{17)}$

This study also demonstrated that the scores on the CDI, a measure related to depression, were reduced despite the fact that the treatment targeted problematic Internet use. 
These scores were further reduced in the follow-up evaluation 1 month after the program was completed. In another study, the subscale related to the emotional symptoms of the Strength and Difficulties Questionnaire after group therapy for adolescents with problematic Internet use also reported that the effect size was larger in the 6 month follow-up evaluation than at the end of the program. ${ }^{22}$ Other problematic Internet use group therapy studies also reported a decrease in depression after treatment. ${ }^{17)}$ Yen et al. ${ }^{23)}$ reported that problematic Internet use and depression increased mutual vulnerability and shared genetic and environmental risk factors. Young suggested that problematic Internet users may forget their stress during Internet access hours, which is similar to drinking alcohol as a form of escape. ${ }^{4)}$ Therefore, depression is the leading cause of problematic Internet use. In addition, the use of the Internet as an compulsive behavior for solving social isolation, loneliness, or negative and nervous emotional states was observed in Internet addiction patients. ${ }^{24)}$ Therefore, CBT is used to restore the emotional state, and the use of the Internet as a compulsive behavior is replaced by a new healthy method to prevent recurrence.

Similar to depression, in relation to anxiety, SAI scores were significantly lower after the program, and the effect was maintained at the 1 month follow-up evaluation. TAI scores did not significantly decrease after the program, which is consistent with the findings of previous studies. ${ }^{14)}$ Previous studies have demonstrated a high level of social anxiety among adolescents with problematic Internet use. ${ }^{25)}$ In addition, loneliness, shyness, and avoidance of social relationships are associated with problematic Internet use. ${ }^{26,27)}$ Finally, to reduce anxiety, socially unstable individuals prefer to communicate via the Internet with a low risk of social communication and therefore exhibit vulnerability to problematic Internet use. $^{28)}$ Thus, it is assumed that these individuals have addressed the mutual improvement result by not only reducing Internet use via group CBT, but also by experiencing positive social communication opportunities.

In this study, participants in the program and their parents were very receptive, as observed by the absence of any dropouts. The reason for the lack of dropouts is that the definition of 'Internet addiction' itself is vague, and a definite diagnostic system has not been established, ${ }^{29,30)}$ which makes it less important to stigmatize the psychiatric illness. Therefore, in the case of patients with depressive disorder or anxiety disorder who have problematic Internet use simultaneously, a therapeutic approach based on problematic Internet use treatment, which is relatively less resistant, can be considered.

In this study, the treatment effect was maintained when the IAS, CDI, and State-Trait Anxiety Inventory were evalu- ated at the 1 month follow-up. It seems that a follow-up evaluation study will be needed at several time points in the future, given the results of a study in China wherein the treatment effect in the Internet addiction group was maintained even after 6 months, based on scores on the scales measuring Internet addiction, depression, and anxiety. ${ }^{22)}$

The limitations of this study are as follows. First, it is difficult to generalize these conclusions to all students because it is a program implemented in one specific female middle school and one industrial high school. Second, there was no control group; therefore, the possibility of changing the score of the evaluation tool by the group variable was not corrected. Third, we relied on self-report evaluation scales and did not seek evaluations from teachers, parents, or clinicians. Fourth, only voluntary participants with a willingness to decrease problematic Internet use participated in the study. Therefore, it is possible that the Pygmalion effect might have affected the outcome from the expectation that the subjects should improve. However, the prevalence of these prejudices seems to be low, given that the TAI scores were almost unchanged before and after the program.

\section{CONCLUSION}

In this study, students who were assessed as problematic Internet users attended group CBT to improve Internet addiction. As a result, students' time spent on the Internet decreased and the degree of addiction improved. In addition, group CBT was effective in alleviating concurrent depression and anxiety symptoms, and the treatment efficacy up to 1 month was considered to be maintained. Larger-scale, longterm studies should be conducted in the future.

\section{Acknowledgments}

This work was supported by the National Research Foundation of Korea (NRF) grant funded by the Korean Government (NRF2014R1A1A2057866 and 2017R1D1A1B03031680).

\section{Conflicts of Interest}

The authors have no financial conflicts of interest.

\section{REFERENCES}

1) Ministry of Science ICT and Future Planning, Korea Internet \& Security Agency. 2015 Survey on the Internet usage. Seoul: Korea Internet \& Security Agency;2015.

2) Goldberg I. Internet addiction disorder (1996) [cited 2004 Nov 24]. Available from: http://users.rider.edu/ suler/psycyber/supportgp. html.

3) American Psychiatric Association. Diagnostic and Stastical Manual of Mental Disorders. 4th ed. Washington, DC: American Psychiatric Association Publishing;1994.

4) Young KS. Internet addiction: the emergence of a new clinical disorder. Cyberpsychol Behav 1998;1:237-244.

5) Petersen KU, Weymann N, Schelb Y, Thiel R, Thomasius R. [Path- 
ological Internet use--epidemiology, diagnostics, co-occurring disorders and treatment]. Fortschr Neurol Psychiatr 2009;77:263-271.

6) Ha JH, Yoo HJ, Cho IH, Chin B, Shin D, Kim JH. Psychiatric comorbidity assessed in Korean children and adolescents who screen positive for Internet addiction. J Clin Psychiatry 2006;67:821-826.

7) Ko CH, Yen JY, Yen CF, Chen CS, Chen CC. The association between Internet addiction and psychiatric disorder: a review of the literature. Eur Psychiatry 2012;27:1-8.

8) Ministry of Science ICT and Future Planning, National Information Society Agency. Survey on Internet Addiction, 2014. Seoul: Ministry of Science ICT and Future Planning, National Information Society Agency;2015.

9) Parker JD, Taylor RN, Eastabrook JM, Schell SL, Wood LM. Problem gambling in adolescence: relationships with Internet misuse, gaming abuse and emotional intelligence. Pers Individ Dif 2008;45: 174-180.

10) Young KS. Internet addiction: a new clinical phenomenon and its consequences. Am Behav Sci 2004;48:402-415.

11) Ko CH, Liu GC, Yen JY, Chen CY, Yen CF, Chen CS. Brain correlates of craving for online gaming under cue exposure in subjects with Internet gaming addiction and in remitted subjects. Addict Biol 2013;18:559-569.

12) Ko CH, Liu GC, Hsiao S, Yen JY, Yang MJ, Lin WC, et al. Brain activities associated with gaming urge of online gaming addiction. $\mathrm{J}$ Psychiatr Res 2009;43:739-747.

13) Grant JE, Potenza MN, Weinstein A, Gorelick DA. Introduction to behavioral addictions. Am J Drug Alcohol Abuse 2010;36:233-241.

14) Lee HC. A study on developing the Internet game addiction diagnostic scale and the effectiveness of cognitive-behavioral therapy for Internet game addiction [dissertation]. Seoul: Korea Univ.;2001.

15) Craig SD, Driscoll DM, Gholson B. Constructing knowledge from dialog in an intelligent tutoring system: Interactive learning, vicarious learning, and pedagogical agents. J Educ Multimed Hypermed 2004;13:163-183.

16) Northen H. Clinical social work: knowledge and skills. 2nd ed. New York, NY: Columbia University Press; 1995.

17) Winkler A, Dörsing B, Rief W, Shen Y, Glombiewski JA. Treatment of Internet addiction: a meta-analysis. Clin Psychol Rev 2013;33:317-
329.

18) Kang MC, Oh IS. Development of Korean Internet addiction scales. Korean J Youth Counsel 2001;9:114-135.

19) Young KS. Caught in the net: how to recognize the signs of Internet addiction--and a winning strategy for recovery. New York, NY: John Wiley \& Sons;1998.

20) Smucker MR, Craighead WE, Craighead LW, Green BJ. Normative and reliability data for the Children's Depression Inventory. J Abnorm Child Psychol 1986;14:25-39.

21) Spielberger CD, Gorsuch RL, Lushene RE. The State-Trait Anxiety Inventory. Palo Alto, CA: Consulting Psychologists Press;1970.

22) Du YS, Jiang W, Vance A. Longer term effect of randomized, controlled group cognitive behavioural therapy for Internet addiction in adolescent students in Shanghai. Aust N Z J Psychiatry 2010;44: 129-134.

23) Yen JY, Ko CH, Yen CF, Chen SH, Chung WL, Chen CC. Psychiatric symptoms in adolescents with Internet addiction: comparison with substance use. Psychiatry Clin Neurosci 2008;62:9-16.

24) Young KS. Cognitive behavior therapy with Internet addicts: treatment outcomes and implications. Cyberpsychol Behav 2007;10:671679 .

25) Yen JY, Ko CH, Yen CF, Wu HY, Yang MJ. The comorbid psychiatric symptoms of Internet addiction: attention deficit and hyperactivity disorder (ADHD), depression, social phobia, and hostility. J Adolesc Health 2007;41:93-98.

26) Yuen CN, Lavin MJ. Internet dependence in the collegiate population: the role of shyness. Cyberpsychol Behav 2004;7:379-383.

27) Ceyhan AA, Ceyhan E. Loneliness, depression, and computer selfefficacy as predictors of problematic Internet use. Cyberpsychol Behav 2008;11:699-701.

28) Weinstein A, Dorani D, Elhadif R, Bukovza Y, Yarmulnik A, Dannon $P$. Internet addiction is associated with social anxiety in young adults. Ann Clin Psychiatry 2015;27:4-9.

29) Pies R. Should DSM-V designate "Internet Addiction" a mental disorder? Psychiatry (Edgmont) 2009;6:31-37.

30) Frances AJ, Widiger T. Psychiatric diagnosis: lessons from the DSM-IV past and cautions for the DSM-5 future. Annu Rev Clin Psychol 2012;8:109-130. 